\title{
Analysis of selected diagnostic issues related to the process of constructing multimedia mobile scenes
}

\author{
Marcin Łukasiewicz ${ }^{1, *}$ Aleksandr Dykha $^{2}$, Ronald M. Martinod ${ }^{3}$ \\ ${ }^{1}$ Bydgoszcz University of Science and Technology, Faculty of Mechanical Engineering, Al. prof. S. \\ Kaliskiego 7, 85-796 Bydgoszcz, Poland \\ ${ }^{2}$ Khmelnytsky National University, 29016, 11, Instytutska Street, Khmelnitsky, Ukraine \\ ${ }^{3}$ EAFIT University, Faculty of Mechanical Engineering, Carrera 49 N 7 sur 50, Colombia
}

\begin{abstract}
New design solutions for multimedia mobile scenes require the development and analysis of possible implementation of technical condition assessment procedures. The process of operation and diagnostics of multimedia mobile scenes depends on the diagnostic susceptibility, the guidelines for handling scenes should be taken into account already at the stage of the design and construction process, which reduces or eliminates the risk and increases the safety of mobile multimedia scenes.
\end{abstract}

\section{Introduction}

Mobile multimedia scenes treated as large-size objects pose a great challenge for designers due to the need to adapt their geometric and material features. An important problem to be solved is to ensure the minimum time of disassembly and assembly of the mobile stage, which, apart from safety, is a priority in terms of increasing competitiveness in relation to the design solutions of multimedia scenes available on the market.

The process of operation and diagnostics of mobile multimedia scenes also depends on the diagnostic susceptibility, the guidelines for handling scenes should be taken into account at the stage of the design and construction process, which reduces or eliminates the risk and increases the safety of mobile multimedia scenes.

One of the important aspects of the designer's work is the proper conduct of the entire construction process. A person designing new objects should follow certain guidelines, on the basis of which the execution of the designed element should be as technologically simplest as possible, while remembering to minimize the costs of its production. The creation of new objects with a specific purpose, such as mobile scenes, creates a number of problems to be solved that must be taken into account at the design stage. These are not only aesthetic and safety aspects that affect the functional level, but also the issues of technical audio-video solutions, which will testify to the reception of the finished product by both investors and recipients watching stage performances.

\footnotetext{
*Corresponding author: mlukas@pbs.edu.pl
} 
The following paper will discuss selected aspects related to the selection of construction materials, the problem of diagnosing the condition and minimizing the risk factors associated with the creation of a new, technically complex object, which is a multimedia mobile scene.

\section{Analysis of the properties of selected construction materials}

The variety and availability of construction materials for the construction of multimedia mobile scenes is very wide and it is the designer who will largely determine what materials will be used during the construction of mobile stages. Due to the fact that such a stage will be placed on a semitrailer of a tractor unit, the constructor must ensure the selection of materials that meet the strength criteria, safety criteria and the criterion of total weight, which is determined by the weight allowed for traffic in road traffic regulations [1].

The most commonly used construction materials used in machine construction include two basic groups of materials: metal construction materials and non-metal construction materials. The general division of construction materials is shown in Figure 1.

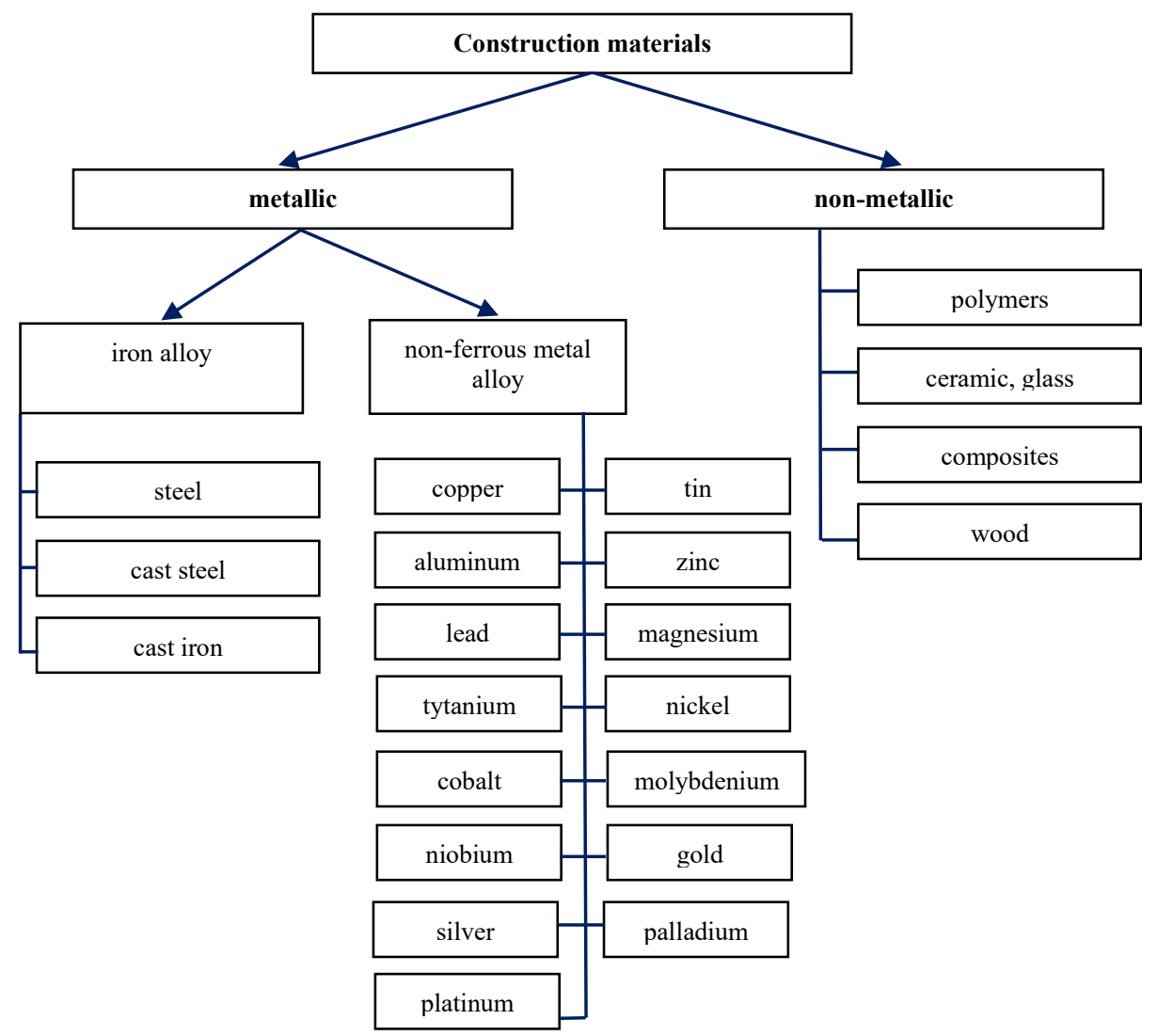

Fig.1. Basic division of construction materials [2].

Metal materials - this group includes mainly alloyed and unalloyed steels, carbon and alloy cast steels, alloy and carbon cast irons, and the entire group of non-ferrous metal alloys [2]. Metals are characterized by high values of modulus of elasticity. The mechanical properties of metals can be modified by applying heat treatment and machining. A characteristic feature of metals is their ductility, which allows the metal to be deformed - 
plastic working. The advantage of the ductility of metals is their resistance to fatigue. The greatest disadvantages of metal materials include the lowest resistance of metals to corrosion.

Non-metallic materials - this group of construction materials includes mainly wood in various forms, ceramic sinters, cermet's, polymer plastics, polymer composites, in particular glass fibres and carbon fibres [3].

Ceramics and glass - just like metals, construction materials with high values of the elasticity modulus, but unlike metals, these materials are brittle. Exposing glass and ceramics to tensile and compressive loads causes damage in the material in the form of brittle fractures or crushing. Ceramics are not stretchy, they are characterized by low resistance of the material to local stress concentrations [4]. With respect to metals, these material groups are not easy to use as construction materials.

Polymers and elastomers - the value of the modulus of elasticity of polymers is approximately fifty times lower than that of metals, but their mechanical strength can be compared with metals. The properties of polymers strongly depend on the ambient temperature - already at room temperature, polymers can flow under the action of load, which means that their geometric shape after loading may significantly differ from the original shape. Polymers do not have any functional strength properties at temperatures above $200^{\circ} \mathrm{C}$. They are characterized by a strength-to-density ratio comparable to metals and are very useful in the manufacture of products with a complex geometric shape [4]. The polymers are resistant to corrosion and are characterized by low values of the coefficient of friction.

Composites - light, stiff, durable construction materials, partially resistant to impact loads. Most of the composite solutions are based on the use of a polymer epoxy or polyester matrix, in which there is a fiberglass, carbon fiber reinforcing the material. Due to the softening of the polymer, composites with a polymer matrix cannot be used at temperatures above $250^{\circ} \mathrm{C}$, the best properties are achieved at room temperatures. The cost of using composite materials is very high, therefore their use as a construction material should be a well-thought-out process, based on appropriate economic and material-strength calculations justifying their use [4].

It should be noted that due to the wide range of availability of construction materials, the materials are subject to normative processes and are described in detail in world, European and national standards, as well as industry standards. Due to the participation of Poland in the structures of the European Union, it forces the harmonization of national standards with the EU PN-EN and the resulting harmonization of symbols and appropriate mechanical properties of materials [5].

A wide group of construction materials requires the use of certain selection criteria, on the basis of which the constructor will propose optimal material solutions at the design stage. The correct selection of construction materials is an important and complicated process. With regard to mechanical structures, two basic criteria for selecting materials are used: general and specific criteria (mechanical, tribological, thermal) [3].

General criteria - they are mainly related to the unit price and the availability of construction material. An important feature of the material analysed when selecting it for a specific mechanical structure is density, as this feature significantly determines the weight of the structure and indirectly translates into energy consumption during operation.

Mechanical criteria - the first basic group included in the detailed criteria has a direct impact on the selection of construction materials that meet the design assumptions of the newly created technical facility. When selecting a construction material, the following properties must be taken into account: modulus of elasticity (longitudinal, transverse, volumetric), static strength, fatigue strength, fracture toughness and vibration damping coefficient [3]. 
Tribological criteria - division of materials with regard to the features characterizing the resistance of the material to abrasive wear, frictional properties through the analysis of the slip coefficient and rolling friction [6].

Thermal criteria - division of construction materials with regard to thermal properties, which include: thermal conductivity, specific heat, linear expansion coefficient, melting point, glass transition temperature in the case of polymeric materials and glasses, and creep resistance [3].

When analysing the above criteria when designing multimedia mobile scenes, some criteria will be the leading values, while others will be auxiliary. For example, completely different criteria will be set for the supporting structure of the mobile stage, the materials of which should be characterized by high fatigue strength, stiffness described by the modulus of elasticity, while in the case of the roof structure of the mobile stage, the main criterion will be mass. Therefore, we can see that complex technical objects must be based on a number of construction materials, depending on the purpose or function performed by the element or kinematic node, taking into account the type and nature of the load and variable operating conditions [7].

\section{Selected aspects of the mobile scenes diagnostics theory}

The essence of diagnostics of mobile scenes consists in determining the condition of the object indirectly, without dismantling, based on the measurement of generated diagnostic signals and comparing them with nominal values [8].

The tasks of diagnostics of mobile scenes come down to the definition of three basic pillars:

Pillar I - identification, classification and research - selection of symptoms describing the technical condition of the mobile scene;

Pillar II - research methodology - selection of methods and means for the implementation of the research procedure;

Pillar III - diagnostic decision - assessment of the technical condition of the stage along with the definition of preventive measures.

The purpose of diagnostic tests for mobile scenes is to determine the technical condition of the system. The term technical condition should be understood as a specific set of processes taking place in the system, as well as its structure. The state of the system is therefore a set of numerical values of the variables describing the system at a given moment [9].

Each state of the system can be expressed by a set of numerical values characterizing its structure and the intensity of separate processes taking place in the system. Defining quantitative changes as changes in the flow of energy, which allows the diagnosis in terms of energy. Diagnostics is therefore the study of the reaction of the mobile scene to energy interactions causing a change in its state. The quantitative or qualitative change of the energy itself can be a source of information about the technical condition of the mobile stage, which allows the implementation of the activities of the validation and optimization process of measuring points. This allows the use of energy as an information carrier when it is inherently related to the existence of a mobile scene, and also when it is brought from the outside only to determine the scene's state on its basis [8].

The diagnostically used energy transformation is caused by the technical condition of the mobile stage, and its characteristics are related to the structure and properties of the tested object. In order to determine the state of the mobile scene, the values selected to describe this state of physical quantities should be measured. $[9,10]$.

The presented principles apply to cases where one physical quantity (state symptom) is used to describe the technical condition of a mobile scene. Much greater difficulties occur in 
the cases of diagnosing complex systems, in which the necessity of simultaneous implementation of many tasks was assumed. In such cases, the description of the condition must include the determination of specific values for many of the symptoms of the condition.

Apart from technical difficulties, there are also interpretation issues, especially when the diagnosis precedes the operational decision. In this case, it is necessary to implement methods that allow for quantitative and qualitative optimization [11,12]

The destruction of the state of the mobile stage along with the causes of design, manufacturing and operational defects as well as random factors disrupting the normal functioning of the stage justify the need to implement the technical condition assessment process, which allows to make:

- studies of physic-chemical processes enabling the determination of a set of diagnostic parameters (state symptoms);

- establishing sets of independent and complete state features (number of states) and diagnostic parameters;

- searching for a diagnostic model;

- establishing the algorithms of the check sets;

- ensuring the appropriate diagnostic susceptibility of the mobile scene;

- development of reasonable methods and diagnostic devices.

The division of diagnostic methods is presented schematically in Figure 2 [8].

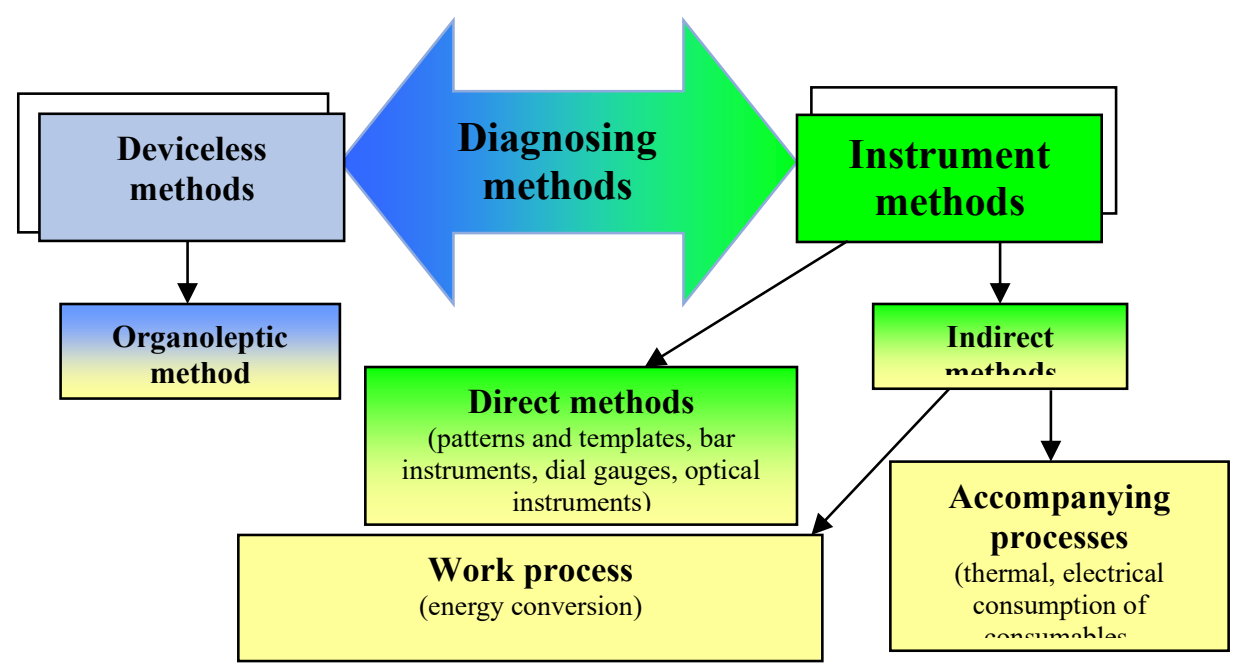

Fig.2. Classification of methods for diagnosing mobile scenes.

The implemented diagnostic issues are assessed in terms of:

- economic efficiency;

- reliability;

- operational safety of the operation.

Meeting the expectations of the diagnostics process forces actions in the area of minimizing the problems generated during the implementation of the process of assessing the technical condition of the mobile scene, such as [8]:

- acquisition and processing of diagnostic information;

- building models and diagnostic relationships;

- diagnostic inference and limit value determination;

- classification of the states of the mobile stage;

- predicting the time of the next diagnosis; 
- imaging decision-making information.

Shaping and assessing the quality of the mobile scene with the use of diagnostic methods is closely related to the need to maintain their functional characteristics at an appropriate level in specific operating conditions. These features, meeting the requirements representative for the condition of the object, should be determined already at the stage of evaluation, design and construction, and verified during production and operation $[9,13]$.

The above thematic groups are the area of interest in the field of methods and methodology of shaping and maintaining the quality of mobile scenes, which is conditioned by the dynamic development of the following issues:

- diagnostic modelling;

- methods of diagnosis, genesis and forecasting;

- diagnostic susceptibility;

- construction of economic and accurate means of diagnosis;

- precision of the diagnostic possibilities in the next phases of the existence of mobile scenes.

The presented problems and challenges of the coming times are by necessity fragmentary and they only present selected issues shaping the state of diagnosing mobile scenes. The process of implementing diagnostic issues has been widely described in the literature by $\mathrm{C}$. Cempel, S. Niziński, B. Żółtowski $[9,14,15,16]$.

\subsection{Diagnostic susceptibility of multimedia mobile scenes}

Adaptation of a technical object to the implementation of operation and maintenance processes is called its operational susceptibility. The following types of object vulnerabilities are distinguished $[17,18,19]$ :

- utility;

- diagnostic;

- maintenance;

- restorative;

- utilization.

Diagnostic susceptibility of mobile scenes is one of the components of operational susceptibility, determined as a set of features defining the adaptation of a mobile scene to operation under specific conditions. It is an important element of the diagnosis process, which has a significant impact on its quality, implementation time, ease of carrying out, costs and accuracy of diagnosis. Vulnerability can be assessed on the basis of indicators called diagnostic susceptibility indicators. Due to their nature and thematic scope, the diagnostic susceptibility indicators can be divided into:

- diagnostic indicators;

- diagnostic technological indicators;

- operational indicators;

- economic indicators.

Diagnostic susceptibility indicators are specified in detail in the literature $[13,17]$. There is a need to adapt mobile scenes to a quick and reliable assessment of the technical condition. It requires introducing, during the design and construction of the mobile scene, a number of activities determining the diagnostic susceptibility and covering its area $[8,20]$ :

- identification of aging and damage processes;

- description of the requirements for the construction of mobile scenes, including the use of selected diagnostic methods;

- validation of the level of diagnosis and definition of actions aimed at improving the diagnostic susceptibility of mobile scenes;

- determining the advisability of diagnosing individual complexes of the facility, 
- conducting trials to diagnose the prototype of the mobile scene;

- making diagnostic characteristics of mobile scenes;

- cost assessment of the design, production and operation of mobile scenes;

- development of recommendations for the implementation of the process of diagnosing mobile scenes;

- analysis of possible diagnostic methods;

- selection of diagnostic points.

Diagnostic compliance can also be shaped by improving diagnostic methods and algorithms. When analysing the diagnostic susceptibility in a holistic approach, it should be defined as the diagnostic susceptibility of the diagnostic system of mobile scenes, understood as composed of the following subsystems: the diagnosis subsystem and the diagnosing subsystem. The diagnostic susceptibility defined in this way allows for the generation of two basic components: $[8,13,16]$ :

Diagnosis sensed by:

- the degree of automation of diagnostic activities;

- interaction of diagnosis with the control of mobile scenes;

- effectiveness and credibility of the method of diagnosis;

- diagnostic methods that can be used.

Diagnostic technological performance as sensed by:

- access to diagnosis sites;

- minimization of labour consumption and costs of diagnosis;

- easy connection of diagnostic means,

- object sensing during production;

- unification of measuring points;

- convenience of work during diagnosis;

- possibility of diagnosing without disassembling the systems.

Thus, the development of the diagnostic susceptibility of mobile scenes covers the entire "life" cycle of this type of technical object. If the process of shaping the diagnostic susceptibility is not consciously controlled, a product is obtained that often causes great difficulties in its diagnosis, the need to use unique, and therefore costly devices, timeconsuming methods, etc. $[16,18]$

The optimization of the diagnostic susceptibility assessment process should include $[8,14,20]$ :

- functional analysis,

- construction identification,

- diagnostic identification,

- determination of diagnostic susceptibility indicators,

- determination of diagnostic points characterized by a correlation of changes in the symptomatic value depending on the change in the technical condition,

- developing conclusions and recommendations.

Optimization of diagnostic susceptibility takes place during the design and construction of mobile scenes, material preparation and control - during production, and practical checking, use and improvement - during operation.

\subsection{Method of validating the selection of measurement points}

An important element of dynamic state modelling is the methodology of validating the selection of measurement points due to the variety of phenomena occurring during the operation of mobile scenes. It is necessary to identify the location of the measurement points and carry out the procedure of their validation. The characteristics of the coherence method, 
which is one of the basic methods for validating the selection of measurement points, are presented below.

The coherence method is based on the properties of the defined coherence function as a measure of the correlation of vibration signals in the frequency domain. It determines the similarity (coherence) of vibration processes with the previously described properties [14, 20,21]. This function takes the form according to dependency 1 as:

$$
\gamma_{x y}^{2}(f) \equiv \frac{\left|G_{x y}(f)\right|^{2}}{G_{x x}(f) G_{y y}(f)}
$$

The mathematical foundations of determining the coherence function are based on the determination of the time courses of vibration signals determined by the relationship:

$$
\begin{aligned}
& x(t)=A_{1} \sin \left(\omega t+\varphi_{x}\right) ; \\
& y(t)=A_{21} \sin \left(\omega t+\varphi_{y}\right)
\end{aligned}
$$

On the basis of the obtained time courses, using the Fourier transform of vibration signals, spectra of vibration signals described by the relationship:

$$
X(f)=\int_{-\infty}^{\infty} x(t) e^{-j 2 \pi f t} d t ; \quad Y(f)=\int_{-\infty}^{\infty} y(t) e^{-j 2 \pi f t} d t
$$

The next step in determining the coherence function is to obtain the values of the own and mutual spectral densities of vibration signals being components of the coherence function according to the dependencies presented below:

$$
\begin{aligned}
& G_{x x}=\lim _{T \rightarrow \infty} \frac{1}{T} \int_{0}^{T}\left\{A_{1} \sin \left[\omega t+\phi_{x 1}\right]\right\} \cdot\left\{A_{2} \sin \left[(\omega t+\tau)+\phi_{x 2}\right]\right\} e^{-j 2 \pi f t} d t \\
& G_{y y}=\lim _{T \rightarrow \infty} \frac{1}{T} \int_{0}^{T}\left\{A_{1} \sin \left[\omega t+\phi_{y 1}\right]\right\} \cdot\left\{A_{2} \sin \left[(\omega t+\tau)+\phi_{y 2}\right]\right\} e^{-j 2 \pi f t} d t \\
& G_{x y}=\lim _{T \rightarrow \infty} \frac{1}{T} \int_{0}^{T}\left\{A_{x} \sin \left[\omega t+\phi_{x}\right]\right\} \cdot\left\{A_{y} \sin \left[(\omega t+\tau)+\phi_{y}\right]\right\} e^{-j 2 \pi f t} d t
\end{aligned}
$$

Knowing the density of the source process and the transfer function, it is possible to transform the dependencies 4, 5, 6 to the forms described by the following dependencies:

$$
\begin{aligned}
G_{x y}(f) & =h_{1}(f) h_{2}^{*}(f) G_{u u}(f) \\
G_{x x}(f) & =\left|h_{1}(f)\right|^{2} G_{u u}(f) \\
G_{y y}(f) & =\left|h_{2}(f)\right|^{2} G_{u u}(f)
\end{aligned}
$$

Taking the dependencies into account, the expression 1 above takes the form:

$$
\gamma_{x y}^{2}(f)=\frac{\left|h_{1}(f) h_{2}^{*}(f)\right|^{2} G_{u u}^{2}(f)}{\left|h_{1}(f)\right|^{2} G_{u u}(f) h_{2}(f)^{2} G_{u u}(f)} \leq 1
$$

Function values can vary within limits: $0 \leq \gamma_{x y}^{2}(f) \leq 1$. In linear systems with constant parameters, the value of the coherence function for all frequencies $f$ will be equal to one. This means that the processes $\mathrm{x}(\mathrm{t})$ and $\mathrm{y}(\mathrm{t})$ are completely correlated, dependent $[14,20$, $21,22,23]$.

If $x(t)$ and $y(t)$ are completely uncorrelated, random processes, the independent function value will be zero. In the case where the value of the coherence function is greater than zero, but less than one, there is a possibility that there is noise in the signal disturbing the measurement or non-linearity of the system through which the signal representing the fault 
occurs. Figure 3 shows the procedure of determining the coherence function.

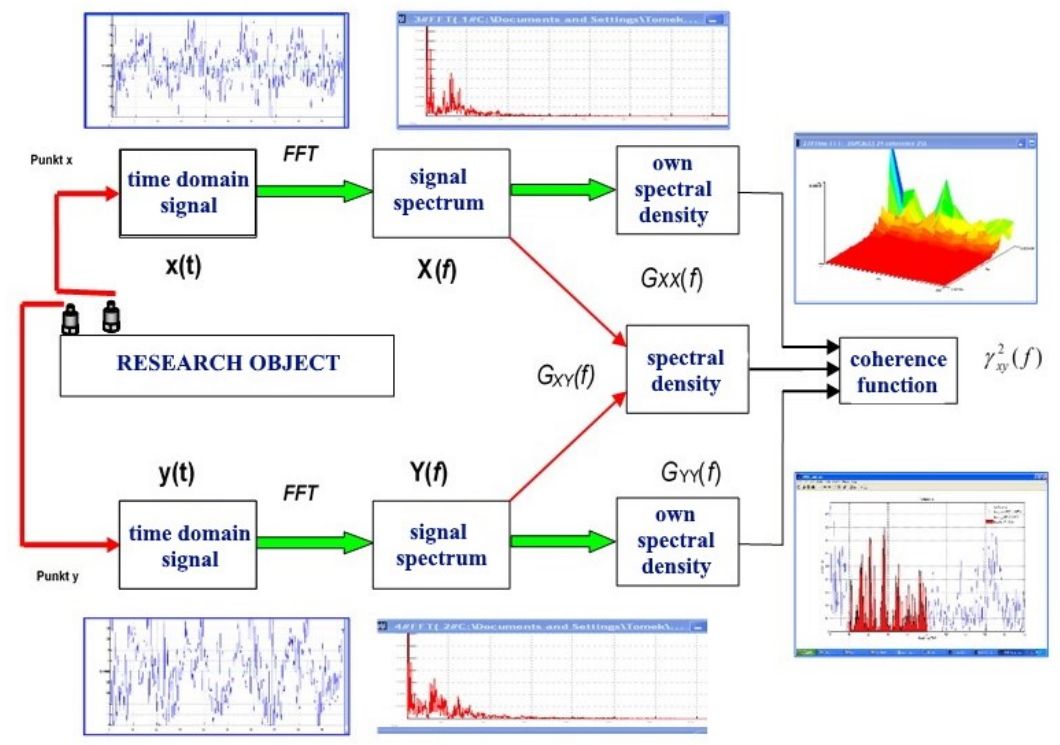

Fig.3. Procedure for determining the coherence function.

The model of the signal transition from the source to a specific point on the wall of the test object presented in Figure 3 does not reflect their transition correctly. Additionally, the model should assume multi-path transitions of the information signal $\mathrm{x}(\mathrm{t})$ and the interfering signals, which results from the construction of multimedia mobile scenes.

\section{Risk and technical security of the mobile stage}

The Machinery Directive 2006/42/EC and the strictly related possibility of certifying a product with the CE mark obliges each machine manufacturer to carry out the so-called assessment of the risks that a given machine may pose at the time of operation, thus posing a real threat to total or partial loss of life or health. Due to the fact that the structure of the mobile stage with the accessories (e.g. hydraulic system) is mounted on the trailer, in the light of the directive in force, its selected elements are considered to be a set ready to be installed and capable of functioning in a given state only if it is mounted on the selected means of transport. Pursuant to the provisions of the Machinery Directive, the mobile stage, or rather its selected elements, which are indicated in the aforementioned Directive, must be designed and constructed taking into account the results of the risk assessment.

The Machinery Directive does not in itself explain the concept of risk or safety. The most frequently used standards from the group of standards harmonized with the Machinery Directive are: PN-EN ISO 12100: 2012, PN-EN ISO 12100-1: 2005 and PN-EN ISO 121002: 2005. These standards contain information on the safety of machinery, ranging from explaining the basic concepts, presenting the methodology of conduct, technical design principles, and ending with risk assessment and methods of reducing it. It is in the standard [24] that the basic definition of risk appears as a combination of the probability of harm occurrence and the severity of this harm.

The content of this standard also distinguishes the concept of residual risk, which remains after the application of protective measures. Therefore, in light of these definitions, the key 
task of risk assessment is to reduce it by applying appropriate protective measures for both the operator and bystanders.

The process of risk assessment and risk reduction begins with the machine design stage. This action follows directly from the strategy presented in the standard [25], towards which the designer should take actions in the following order:

- define the limitations for the machine, including the intended use of the machine and any foreseeable misuse,

- identify threats and the associated emergency situations,

- assess the risk for each identified threat and threat situation,

- apply a risk evaluation and decide whether it is necessary to reduce it,

- eliminate the hazard or reduce the associated risk with the risk using available protective measures [25].

The first four activities presented by the designer will therefore relate to the risk assessment, while the last action at the end of the discussed strategy will concern the reduction of this risk, if necessary. The preparation of each stage should follow the decomposition of the machine into subsystems. The decomposition of the machine in the light of the risk assessment should be divided into two parts: one concerning the control system and the other executive.

A risk assessment is therefore a series of logical steps that enable a structured analysis and evaluation of the risks associated with a given machine. In the first step, the aim is to determine the main and detailed functions of the analysed machine understood as a description of the foreseen and unforeseen use of the machine. Unforeseen actions are all events in which there is a loss of control over the machine resulting from damage or unauthorized behaviour. The first step is also the place where you should indicate the conditions in which the machine can operate without creating potential threats. The next step is the most important stage of the risk assessment, in which the threats that the machine may cause during its operation are listed. At this stage, it is also worth using other standards [eg: ISO / TR 14121-1], which present other methods of threats identification. It is important that the consideration of individual threats is carried out in the perspective of all seven phases of the machine's life $[25,26]$.

After identifying individual threats, it remains to carry out a risk assessment in accordance with the formula [25]:

$$
\mathrm{R}=\mathrm{s} \cdot \mathrm{p}
$$

where:

$R$ - the risk related to the considered threats,

$s$ - the severity of the damage that could result from the threat under consideration,

$p$ - damage occurring probability.

Risk analysis provides the data needed to conduct a risk evaluation and make a decision related to further risk management. It usually takes into account the probability of the risk consequences and the consequences of these consequences. The probability of the occurrence of damage should be considered in three cases:

- the exposure of people to the threats;

- occurrence of a dangerous event;

- the possibility of avoiding or limiting the harm.

In the analysis, one should independently adopt an appropriate scale of the values of individual parameters. After the risk is assessed, the need for preventive measures in the machine or for its operator is determined. Risk evaluation should be undertaken using the three-step risk reduction method. 


\section{Conclusions}

In the process of designing new construction solutions for technical objects, there is no determined method for creating a new solution. Based on the description of the need, an optimal solution is searched for that will meet most of the criteria for the purpose of the object being created. Knowledge about the properties of the material and its physical and mechanical parameters is insufficient in the design process. A constructor using metal materials in particular should know the basic processes of heat treatment technology of these materials, thanks to which we can influence and modify selected properties related to strength and safety. In fact, the possibility of designing a safe structure in itself is rarely possible and it is necessary to refer to the retrofitting of the structure with appropriate additional protective device. The protective device as it stands may, for example, could be a cover which prevents access to the area where there is a mechanical hazard while at the same time reducing the noise level. In the process of assessing the technical condition of mobile scenes, three basic factors stimulating the development of diagnostics should be distinguished: the complexity of the system, the type of traffic performed and reliability. An important element of dynamic state modelling is the methodology of validating the selection of measurement points due to the variety of phenomena occurring during the operation of mobile scenes. It is necessary to identify the location of the measurement points and carry out the procedure of their validation. The coherence method of technical condition assessment presented in the paper requires frequency selection of the diagnostic signal. The number of diagnostic parameters describing the technical condition of mobile scenes is selected depending on the adopted diagnostic model.

\section{References}

1. T. Kalaczynski, V. Martynyuk, J. Boiko, S. Matyukh, S. Petrashchuk. Exploitation aspects of diagnostic hydraulic and pneumatic systems of Multimedia Hybrid Mobile Stages, 19th International conference diagnostics of machines and vehicles hybrid multimedia mobile stage, MATEC Web of Conferences Volume 332 (2021).

2. A. Ciszewski; T. Radomski, A. Szummer. Materiałoznawstwo, Oficyna Wydawnicza Politechniki Warszawskiej, Warszawa (1996).

3. A. Skoć, J. Spałek. Podstawy konstrukcji maszyn. Wydawnictwa Naukowo-Techniczne, WNT Warszawa (2006).

4. M. Ashby. Dobór materiałów w projektowaniu inżynierskim. Wydawnictwa NaukowoTechniczne, Warszawa (1998).

5. L. Dobrzański. Podstawy nauki o materiałach i metaloznawstwo. Materiały inżynierskie $z$ podstaw projektowania materiałowego. Wydawnictwa Naukowo-Techniczne, Warszawa (2002).

6. J. Spałek. 2003. Problemy inżynierii smarowania maszyn w górnictwie. Monografia nr 47. Wydawnictwa Politechniki Śląskiej, Gliwice (2003).

7. S. Augustyn. „A new strategy for developing of space Logistics”, Journal of Konbin 50(1):359-370, (2020).

8. B. Żółtowski. Podstawy diagnostyki maszyn, ATR Bydgoszcz (1996).

9. S. Niziński, R. Michalski. Diagnostyka obiektów technicznych. ITE, Radom (2002).

10. M. Żółtowski, M. Liss, B. Żółtowski, J. Melcer. Truss harbor cranes modal design elements research, Polish Maritime Research, 22, 4(88), s. 84-92, p-ISSN: 1233-258 (2015). 
11. B. Landowski, M. Baran, Analysis of changes in the value of selected lubricant characteristics during use, MATEC Web of Conferences 302, 01009 (2019), 18th International Conference Diagnostics of Machines and Vehicles, pp.1-8, https://doi.org/10.1051/matecconf/201930201009. (2019).

12. J. Wilczarska, E. Kuliś, M. Łukasiewicz, L. Fornal, N. Dluhunovych. The assessment of the impact of the chosen exploational conditions of hydraulic arrangement on the working liquid condition.17TH International Conference Diagnostics Of Machines And Vehicles. Matec Web of Conferences Volume182 Article Number 01026, (2018).

13. B. Żółtowski, S. Niziński. Modelowanie procesów eksploatacji maszyn. ISBN - 83916198-3-4, Bydgoszcz- Sulejówek, s.250 (2002).

14. C. Cempel. Vibroacoustic diagnostics of machines (Diagnostyka wibroakustyczna maszyn). PWN Warszawa (1989).

15. C. Cempel. SVD Decomposition Of Symptom Observation Matrix As The Help In A Quality Assessment Of A Group Of Applications. Diagnostyka v.35. PTDT Warszawa (2005).

16. S. Niziński. Eksploatacja obiektów technicznych. ITE, Radom (2002).

17. M. Woropay (red.). Podstawy racjonalnej eksploatacji maszyn. ITE-ATR, BydgoszczRadom (1996).

18. B. Żółtowski, M. Łukasiewicz, T. Kałaczyński. Information technology in machine condition studies (Techniki informatyczne w badaniach stanu maszyn), Wydawnictwa Uczelniane Uniwersytetu Technologiczno - Przyrodniczego w Bydgoszczy (2012).

19. B. Żółtowski, M. Łukasiewicz. Vibration diagnostics of machines (Diagnostyka drganiowa maszyn), Wydawnictwo Naukowe Instytutu Technologii Eksploatacji, Bydgoszcz - Radom (2012).

20. B. Żółtowski, T. Kałaczyński. Machine diagnostics. Lecture and exercises (Diagnostyka maszyn. Wykład i ćwiczenia), Wydawnictwo Uczelniane Uniwersytetu Technologiczno - Przyrodniczego, Bydgoszcz. (2013).

21. B. Żółtowski, M. Łukasiewicz. Vibration assessment of the consumption of a technical object, Vibroengineering PROCEDIA, 6, p.109-114, (2015).

22. B. Landowski, Ł. Muslewski, Decision model of an operation and maintenance process of city buses, in Proceedings of 58th International Conference of machine design departments, ICMD, Hnanice, Czech Rebublic, (2017).

23. M. Łukasiewicz, T. Kałaczyński, J. Musiał, J.Shalapko. Diagnostics of buggy vehicle transmission gearbox technical state based on modal vibrations, Journal of Vibroengineering, 16, Issue 6, Pages (2624-3168). (2014).

24. Standard: PN-EN ISO 12100-1:2005.

25. Standard. PN-EN ISO 12100:2012.

26. A. Soltysiak, K. Migawa, Application of the Pareto front for risk control in the transport system, $18^{\text {th }}$ International Conference Diagnostic of Machines and Vehicles, 12.12.2019 Bydgoszcz, Poland, MATEC Web of Conferences, vol. 302 (2019).

\section{Acknowledgements}

This paper has been achieved under the research project "Hybrid multimedia mobile scenes are a chance for decisive innovation" No. POIR.04.01.04-00-0045/17-00. 